\title{
Pedagogia antropofágica no APROFUNDAMENTO DO REPERTÓRIO DE SABERES CULTURAIS DE ESTUDANTES DE PEDAGOGIA E SEUS PROFESSORES
}

\author{
ANTHROPOPHAGIC PEDAGOGY IN THE AMPLIFICATION OF \\ THE REPERTORY OF CULTURAL KNOWLEDGE FROM PEDAGOGY \\ UNDERGRADUATE STUDENTS AND THEIR PROFESSORS
}

\begin{abstract}
Ana Cristina Moraes
Professora Adjunta da Universidade Estadual do Ceará (UECE) e Doutora pela Universidade de Campinas (UNICAMP). Vinculada ao Programa de Pós-Graduação em Educação da UECE, Grupo de Pesquisa Investigaçóes sobre Arte, Ensino e História (IARTEH). Fortaleza - CE - Brasil anakrismoraes@hotmail.com

Jacques Therrien

Ph.D. Educação, Cornell University, USA. Professor Visitante e pesquisador da Universidade Estadual do Ceará. Fortaleza - CE - Brasil

jacques@ufc.br
\end{abstract}

Resumo: O texto tematiza a potência de uma Pedagogia Antropofágica na formação inicial de pedagogos, vislumbrando-se o estímulo e a complexificação do repertório de saberes artístico-culturais e experienciais dos estudantes e seus mediadores de aprendizagem. Essa Pedagogia é compreendida como fundante para o aprofundamento de uma formação cultural diversificada nos contextos sócio-políticos, visando criar elementos para a atuação docente, particularmente no referente ao ensino de artes, campo de conhecimento exigido legalmente aos pedagogos. Autores como Tardif (2007), ao discutir saberes e formação docente; Bondía (2002), no referente aos saberes de experiência; Therrien (2010), quando discorre sobre o professor como mediador de saberes; Pimenta (1997; 2006), ao tratar de formação e práxis docente; Libâneo (2002) e Franco (20I2), ao situarem o campo da Pedagogia e da atuação do pedagogo; Zeichner (2008), por trazer um olhar complexo sobre professor reflexivo e seu contexto de atuação; Duarte Junior (2010), quando trata de educação estética; Andrade (1924; 1928) e Barcelos e Silva (2008), ao relacionarem antropofagia cultural e educação, subsidiam teoricamente o estudo. A metodologia de investigação é teórica e empírica, nesta última incluindo dados de entrevistas realizadas com estudantes de Pedagogia de uma universidade pública. A questâo de pesquisa é assim enunciada: Como a universidade contribui para garantir o acesso a bens artístico-culturais a estudantes do curso de Pedagogia? Concluímos que a Pedagogia Antropofágica constitui concepção de formação que agrega açóes educativas de caráter acadêmico e cultural, mobilizadoras de aprendizagens que ampliam horizontes teóricos e práticos necessários à educação estética.

Palavras-chave: Educação Estética. Formação Docente. Pedagogia Antropofágica. Saberes Artístico-Culturais. 
Aвstract: The text thematizes the power of an Anthropophagic Pedagogy in the initial formation of pedagogues, glimpsing the stimulation and the complexity of the repertoire of artistic-cultural and experiential knowledge of the students and their mediators of learning. This Pedagogy is understood as a foundation for deepening a diverse cultural formation in socio-political contexts, aiming to create elements for teaching, particularly in relation to the teaching of arts, a field of knowledge legally required of pedagogues. Authors such as Tardif (2007), when discussing knowledge and teacher training; Bondía (2002), regarding the knowledge of experience; Therrien (2010), when he discusses the teacher as mediator of knowledge; Pimenta (1997; 2006), when dealing with teacher training and praxis; Libâneo (2002) and Franco (2012), placing the field of Pedagogy and the pedagogue's activity; Zeichner (2008), for bringing a complex look on reflexive teacher and its context of action; Duarte Junior (20I0), when it comes to aesthetic education; Andrade (1924, I928) and Barcelos e Silva (2008), when relating cultural anthropophagy and education, theoretically subsidize the study. As a methodological path, it is based on a theoretical and empirical study, including data from interviews developed with students of Pedagogy of a public university. The research problem is transcribed: to what extent has the university been contributing to guarantee access to artistic and cultural goods for students of the Pedagogy course? We conclude that the Anthropophagic Pedagogy constitutes a formation that aggregates educational actions of academic and cultural character, mobilizing learning that broaden theoretical and practical horizons, necessary for aesthetic education.

Keywords: Aesthetic Education. Teacher Training. Anthropophagic Pedagogy. Artistic-Cultural Knowledge.

\section{Introdução}

$\mathrm{O}$ artigo desenvolve uma reflexáo sobre a perspectiva de uma Pedagogia Antropofágica na formação inicial de pedagogos, tendo em vista a ampliação e o aprofundamento do repertório de saberes artísticoculturais e experienciais dos estudantes. Essa Pedagogia é concebida como algo imprescindível à formação cultural e fundante da práxis docente desse profissional, particularmente no âmbito do ensino de $\operatorname{artes}^{1}$, sob pena de exercer precariamente um processo de ensino-aprendizagem com um arsenal de saberes cujos sentidos não domina, nas dimensōes da fruição, da análise ou da produção.

Essas reflexóes partem do pressuposto de que é especialmente com vivências concretas e estudos (teóricos, imersão cultural, fruiçôes) que o estudante de Pedagogia poderá se apropriar de saberes artísticos e de elementos de diferentes culturas, tendo em vista maior fundamentaçáo para sua 
atuação profissional. Referida apropriação se dá, em grande medida, pela incorporação de experiências de caráter antropofágico vivenciadas diretamente pelas pessoas, posto que essa apropriação possui uma razão prática.

Problematiza-se, desse modo, uma compreensão da instituição universitária ${ }^{2}$ a partir da seguinte questão: Até que ponto - e de que modo - a universidade vem contribuindo para garantir o acesso a bens artísticoculturais - no sentido da apreciação, análise e produção - a estudantes do curso de Pedagogia? É indiscutível o potencial dessa instituição para exercer uma função mediadora no acesso a esses bens, sendo que as diretrizes que guiam sua política educacional abrangem variados saberes, dentre eles os estéticos, os artísticos e os culturais. As ações educativas nos âmbitos do ensino, da pesquisa e da extensão podem mobilizar reflexóes e práticas que contribuam para o aprofundamento do repertório cultural dos estudantes e também dos professores universitários, que precisarão nutrir-se de saberes diversificados para fundamentar suas intervençôes pedagógicas. É cabível, então, recomendar a professores universitários, esses mediadores de saberes, que também exercitem a própria formaçáo guiados pela perspectiva da Pedagogia Antropofágica, pois, para que eles se manifestem como mediadores de saberes artístico-culturais, devem possuir esse repertório de tal modo que se torne referência importante para seus alunos, incentivando-os a alimentar incessantemente seus respectivos repertórios.

O caráter antropofágico da proposta pedagógica em foco diz respeito à capacidade 'devoradora' de tudo o que causa estranhamento ao sujeito aprendiz, ou seja, do que para ele é novo, desconhecido e que vai sendo desbravado, engolido, proporcionando olhares diferenciados e inspiradores para a construção de saberes teóricos e práticos (BARCELOS, 2008). Essa ação educativa antropofágica desencadeia processos criativos, dado o acesso a saberes que instigam os 'devoradores' a refletir, a movimentar-se, a pesquisar, a intervir no mundo, enfim, a sentir-se e a ser. Possibilitar a estudantes de Pedagogia um maior acesso aos bens culturais e a experiências estéticas, por meio de diversas linguagens artísticas, torna-se, portanto, um imperativo nas açóes pedagógicas de formação inicial universitária, o que leva a pensar e vivenciar a universidade como polo cultural imprescindível a essa formação.

A formação cultural e estética é uma demanda significativa para o campo da Pedagogia hoje, sendo essas dimensóes assumidas não apenas 
como projeto formativo de educadores, mas também como projeto societário global de caráter unificador e coletivo, como reforça Franco (2012, p. 70-7I): “[...] essa pedagogia precisa educar para romper a dissociaçáo, a falta de comunicação entre cultura e economia, entre afeto e tecnologia, entre necessidade e desejo. [...] precisamos de uma pedagogia que seja tecida com o outro, na perspectiva da dignidade humana."

As reflexôes desenvolvidas a seguir têm por base autores como Tardif (2007), ao discutir saberes e formação docente; Bondía (2002), particularmente no referente aos saberes de experiência; Therrien (20I0), quando discorre sobre o professor como mediador de saberes; Pimenta (I997; 2006), ao tratar de formação e práxis docente; Libâneo (2002) e Franco (20I2), ao situarem o campo da Pedagogia e da atuação do pedagogo; Zeichner (2008), por trazer um olhar complexo sobre professor reflexivo e seu contexto de atuação; Duarte Junior (20I0), quando trata de educação estética; Andrade (1924; I928) e Barcelos e Silva (2008), ao relacionarem antropofagia cultural e educação, dentre outras referências.

\section{Antropofagias, estranhezas e processos de criaçáo no constructo do repertório artístico-cultural de estudantes}

Como forma de transformar em imagem a proposta pedagógica que discutimos aqui, valorizamos, como metáfora, as práticas antropofágicas, mostrando que todo processo de aprendizagem exige acesso e apropriação de saberes diversificados que criam e enriquecem um repertório cultural primordial a qualquer trabalho docente. Dizemos que, num olhar antropológico, tem-se que uma prática antropofágica diz respeito à ação humana de alimentar-se da carne do outro, seja por uma necessidade fisiológica de saciar a fome ${ }^{3}$, seja por atos ritualísticos, espirituais ou de guerras.

A esse respeito, discorre o antropólogo Darcy Ribeiro (1995) baseado nos estudos em comunidades nativas do Brasil. No início da década de I920, o Movimento Modernista brasileiro atribuiu à antropofagia uma dimensão cultural no sentido do alimentar-se de elementos artístico-culturais de diferentes povos, enriquecendo assim a própria produção artística. Um alimentar-se continuamente do outro, transformando a 
energia desse alimento em algo singular, referendando as peculiaridades da cultura local. Oswald de Andrade, um precursor da defesa dessa antropofagia cultural no Brasil, no período referenciado, prescreve, em seus célebres manifestos - o da Poesia Pau-Brasil (1924) e o Antropófago (I928) -, proposiçóes para a criação de uma cultura brasileira liberta das amarras de tantas imposiçóes europeias, não no sentido de negá-la, mas no de devorá-la, fortalecendo ainda mais a rica e diversa cultura nacional, fundamentada nas matrizes indígena, africana e europeia. O significado das intençōes do movimento antropofágico do país, à época, reflete um forte desejo de aprofundamento de identidades nacionais constituídas nos processos de hibridação cultural (CANCLINI, 2008) desde o processo de colonização. Andrade, em seu Manifesto Antropófago (I928), expressa irreverentemente o espírito das práticas antropofágicas ao 'comer' tudo o que interessa do outro para o enriquecimento cultural de seu povo: "Perguntei a um homem o que era o Direito. Ele me respondeu que era a garantia do exercício da possibilidade. Esse homem chamava-se Galli Matias. Comi-o.” (ANDRADE, I928)

O pensamento antropofágico traz, por princípio, a prática "devoradora" de algo que mobiliza, que gera estranhamentos, como reforçam Barcelos e Silva (2008, p. 23 - grifos no original): "[...] a ela só interessa o que lhe é estranho, aquilo que não lhe é familiar no momento. É a partir da deglutição e devoração desse estranho que faremos algo diferente. Esse é um dos principais desafios colocados à educação nos tempos atuais [...]"

Com essa linha de pensamento, defendemos a concepção de uma Pedagogia Antropofágica como forma de complexificação do repertório de saberes necessários à formação e à atuação profissional do pedagogo: uma Pedagogia que agrega um conjunto de açóes educativas de caráter acadêmico e artístico-cultural, mobilizadora de sujeitos em seus processos de aprendizagem e de criação, mais propriamente no estímulo ao alimentar-se continuamente de elementos culturais diversificados que consolidam suas referências teóricas e práticas, seu repertório, tornando-os capazes de compor outros saberes. Saberes referentes ao campo da Pedagogia, como os culturais e artísticos, precisam ser reforçados na formação inicial e continuada dos docentes, numa perspectiva de orientação ética, tendo em vista um projeto societário mais amplo. Assim, "a Pedagogia como ciência será um dispositivo social para contribuir para a reflexáo cotidiana a respeito 
da vida entre homens, realizando contínua vigilância crítica, valorizando projetos emancipatórios e denunciando projetos que oprimem e degradam as possibilidades humanas." (FRANCO, 20I2, p. 7I) Franco também destaca a necessária apreensão de saberes culturais que defendemos, no âmbito desse projeto formativo: "Quando falo de construção da humanidade, quero significar a possibilidade de cada sujeito participar da cultura produzida pelos antepassados, apreendê-la, "degusta-la" e conviver com ela." (id.ib.)

No exercício dessa Pedagogia é fundamental que o estudante exerça concomitantemente estudos teóricos e experimentaçôes práticas de aprendizagens a partir de fatos da própria história de vida, bem como aprofunde os saberes disciplinares do seu campo próprio de atuação junto aos demais saberes da profissão docente, como elencados e discutidos por Tardif (2007). Com a clareza de que esse conjunto de saberes é alimento essencial à sua qualificação profissional, o estudante vai aprendendo a exercitar uma prática antropofágica, buscando continuamente, experimentando, fruindo e criando saberes culturais diversos que tenderão a dilatar seus processos de ensino-aprendizagem de modo mais criativo, dinâmico e interdisciplinar. Esse hábito o credencia para uma 'práxis de mediação', nos processos de ensino e aprendizagem, fundada na sensibilidade de percepção do diferente e do novo constituinte da identidade do sujeito aprendiz e dos seus saberes em expansão. (THERRIEN, 20Io).

[...] são tantas atividades e todas elas são importantes, deixam alguma lembrança, pra citar algumas [...] os momentos vivenciados na disciplina arte-educação, foram momentos únicos, que era como se a disciplina fosse uma caixa de surpresas, sempre tinha uma coisa diferente pra gente fazer, a pintura, o próprio amigo secreto, que a gente tinha que confeccionar [o presente] [...] todas elas sempre mexem com você, quando é no teatro, as apresentaçóes teatrais, você se sente tocado, você se sente sensibilizado e tem a possibilidade de poder estar ali assistindo o seu colega e aplaudindo e observando, "nossa, como ele tem talento, como ele tem qualidade", você tem essa oportunidade de apreciar. [...] são momentos vários e momentos únicos 
e que eles vão gerando outros aprendizados. (Estudante OI, $8^{\circ}$ período, 06/12)

O depoimento exposto realça nossa proposta de uma Pedagogia Antropofágica no curso de Pedagogia. Nele, o estudante destaca os acessos a alguns saberes culturais que teve e como isso lhe foi marcante na formação inicial, proporcionando aprendizagens diversificadas e significativas. Nessa direção, acreditamos que a perspectiva pedagógica das práticas antropofágicas, na formação inicial de pedagogos, precisa ter a universidade como seu polo cultural mobilizador. Um espaço educativo que muitas vezes constitui um dos únicos lugares em que estudantes têm acesso a bens culturais mais aprimorados - menos massificados e mediocrizantes -, com experiências estéticas por via das artes, a exemplo da experiência de uma estudante, no relato a seguir:

Eu já participei de algumas atividades artísticas na Faculdade como espectadora de algumas, principalmente do "Intervalo com Arte"; participei também do [evento] "Contos e Cantos ao Redor do Fogo", onde a gente apresentou, tipo uma contação de história, que realmente valorizava, como eu posso dizer, uma arte bem nordestina, bem cearense, onde o linguajar era o principal foco e as histórias do dia a dia de duas comadres "fuxiqueiras" [fofoqueiras]. [...] também participei do curso de teatro e também na disciplina de Arte-educação, também estimulou muito a gente, [...] mas algumas coisas não deu pra gente ir intensamente, mas se fez com que a gente buscasse também desenvolver esse nosso lado artístico e eu acho que é de grande importância realmente para o pedagogo essa formação artística. (Estudante 02, $7^{\circ}$ Período, 06/I2)

A estudante faz referência a alguns projetos de extensão da universidade analisada que lhe proporcionaram vivências e aprendizagens diversificadas envolvendo o saber artístico, o que nos remete a enfatizar a importância de pensarmos e aprofundarmos açóes que integrem os elementos do tripé universitário - Ensino, Pesquisa e Extensão - visando compor e 
garantir, assim, a complexificação e o enriquecimento da formação inicial de docentes.

\section{O enriquecimento do repertório de saberes artístico- culturais de estudantes por meio de experiências estéticas}

Autores discorrem sobre a necessária ampliação do repertório de saberes dos professores para lhes garantir um olhar e uma atuaçáo mais profundos e com mais possibilidades de situar-se crítica e criativamente no mundo. Zeichner (2008), ao vincular a necessidade da luta por justiça social à postura reflexiva, bem como à proposta de um olhar dos professores sobre a realidade na perspectiva da complexidade e de um amplo repertório de saberes, reforça o caráter ético-político da docência: "A ligação da reflexão docente com a luta por justiça social significa [...] certificar-se que os professores têm o conhecimento de conteúdo e o conhecimento pedagógico que eles precisam para ensinar, de uma maneira que desenvolva a compreensão dos estudantes [...]" (ZEICHNER , 2008, p. 546) Com isso, Zeichner aponta para a busca de aperfeiçoamento do olhar crítico e da postura interventiva do professor sobre o mundo, aliando a suas açóes pedagógicas diferentes saberes culturais - seus e de seus alunos - e um ideal político-militante de defesa dos direitos sociais.

Essa perspectiva situa-se numa lógica de ação pedagógica reflexiva e crítica que é imprescindível para o mediador que anseia por ver suas possibilidades formativas e suas ações pedagógicas cotidianas ampliadas e enriquecidas com um repertório de saberes arejado, dinâmico e atualizado. Estar atento aos movimentos do mundo, com uma atitude devoradora, antropofágica é, pois, o que, com outras palavras, propóe esse autor.

Nossas observaçóes, no contexto das universidades brasileiras, revelam que, em boa medida, há uma constante intenção dos professores universitários de gerar tanto processos de educação estética quanto de educação política nas suas ações pedagógicas. Essa realidade se aproxima bastante da perspectiva defendida por Zeichner (2008), a saber, de exercer uma cultura de reflexividade vislumbrando a intervenção e a análise de um contexto sociopolítico mais amplo. Nessa direção, é recorrente ob- 
servar estudantes universitários apresentarem o seguinte questionamento ${ }^{4}$ : Como viabilizar uma educação estética mobilizada por açôes de extensão e de pesquisa? A indagação desses estudantes reflete uma angústia generalizada permeando seus discursos, ao lado de uma percepçáo de que a política educacional para o ensino superior público está em condição lastimável em algumas instituiçôes, com forte descaso em relação a investimentos básicos - em recursos humanos e em infra-estrutura mínima, por exemplo - para a garantia de uma educação superior de qualidade no país. Assim, evidencia-se que um projeto de educação estética e, consequentemente, de consolidação do repertório de saberes artístico-culturais no âmbito da formação universitária, requer professores que desencadeiem processos instigantes e mobilizadores da sensibilidade de seus educandos. São imprescindíveis, portanto, medidas de apoio institucional e de investimentos financeiros em políticas educacionais capazes de gerar condiçóes para viabilizar açóes pedagógicas adequadas a essa proposta.

No almejado projeto de construção de uma educação estética das pessoas, Schiller (20I I, p. 64) reforça a busca essencial de saberes diversos para a ampliação do repertório cultural das mesmas. Para isso, avalia que é preciso "[...] proporcionar à faculdade receptiva os mais multifacetados contatos com o mundo e elevar ao máximo a passividade do sentimento; [...] conquistar para a faculdade determinante a máxima independência com relação à receptiva e ativar ao extremo a atividade da razáo." (SCHILLER, 20II, p. 64) O autor exalta a necessária força de equilíbrio que precisa haver entre os impulsos racional e sensível do ser humano. A receptividade dos conhecimentos do mundo precisa estar em estado ativo e isso requer autonomia. Autonomia para a busca de saberes e para a intervenção concreta no mundo.

Na mesma linha de intenção - a de possibilitar uma educação estética - Duarte-Junior (20I0) reitera que o sentido dessa educação precisa ser criado a partir de vivências concretas. Tais vivências - ou experiências - não podem se restringir à mera contemplação de obras de artes, "Elas devem, sobretudo, principiar por uma relação dos sentidos com a realidade que se tem ao redor, composta por estímulos visuais, táteis, auditivos, olfativos e gustativos. Há um mundo natural e cultural que precisa ser frequentado com os sentidos atentos [...]" (DUARTE JUNIOR, 20Io, p. 30) $\mathrm{O}$ autor citado discorre sobre a necessidade de os professores formado- 
res desenvolverem sua própria sensibilidade, sua própria educação estética em processo contínuo, com o intuito de conseguirem conduzir a contento outros processos formativos: "[...] na realidade, uma educação sensível só pode ser levada a efeito por educadores cujas sensibilidades tenham sido desenvolvidas e cuidadas, tenham sido trabalhadas como fonte primeira dos saberes e conhecimentos que se pode obter acerca do mundo." (op. cit., p. 3I)

Será, pois, esse educador sensível que poderá desencadear, efetivamente, açóes estético-pedagógicas; afinal, só se pode oferecer o que se possui. Como um professor irá, por exemplo, expor aos estudantes um arsenal de estilos musicais ou experimentar tendências de dança se ele mesmo não conheceu experiencialmente essas linguagens artísticas ou mesmo nunca fez uma pesquisa para tentar, minimamente, conhecer a história, as técnicas ou os artistas que exercem tais linguagens?

\section{Por uma Pedagogia Antropofágica na universidade}


experiência aquilo que 'nos passa', ou que nos toca, ou que nos acontece, e ao nos passar, nos forma e nos transforma. Somente o sujeito da experiência está, portanto, aberto à sua própria transformação." (MORAES, 2002, p. 25-26) Em suma, o saber de experiência se dá "na relação entre o conhecimento e a vida humana.” (id.ib.) O saber da experiência, para ele, se constitui com os sentidos atribuídos pelo sujeito da experiência ao fato experimentado. Nesse sentido, toda experiência é singular.

Não seria essa a pista para uma Pedagogia Antropofágica proposta por Bondía (2002) ao valorizar o saber experiencial? O autor revela uma compreensão da necessária dilatação dos sentidos a partir de açóes concretas e dotadas de sentido para as pessoas, sendo nessa perspectiva que se apreende um projeto de educação estética de caráter antropofágico, ou seja, um processo de amplificaçáo dos sentidos e saberes humanos. Nisso se situa uma educação integral das pessoas pelas experiências estéticas ${ }^{6}$, posto que as mesmas acionam e mobilizam constantemente a cognição, "[...] pela vulnerabilidade aos acontecimentos, estados de espírito, relaçóes com a cultura, saberes múltiplos vindos do corpo e de abstrações, além do que a mente elabora a partir de paisagens do corpo, do ambiente, da memória e da ficção." (MEIRA, 2009, p. 32) Referidos saberes muitas vezes se manifestam agregados a saberes concebidos como lúdicos, também produtos de intervenções pedagógicas. (D’AVILA, 20I4, 20I6)

No caso da formação de pedagogos, diversas proposiçôes legais sobre o enriquecimento estético já estão postas. Dentre essas encontramos as Diretrizes Curriculares Nacionais para a Formação em Nível Superior (cursos de licenciatura, cursos de formação pedagógica para graduados e cursos de segunda graduação) e para a Formação Continuada (2015), assim como as Diretrizes Curriculares Nacionais para o Curso de Pedagogia (2006), que prescrevem elementos de caráter estético para compor os currículos de curso (artigo $3^{\circ}$ e artigo 6o, 2006). Referendado nessas Diretrizes, cada curso de Pedagogia do país precisa compor seu currículo criando ao menos alguns elementos que proporcionem uma base estética a futuros pedagogos (disciplinas obrigatórias, atividades complementares etc.). A atual LDB propóe igualmente uma formação integral das pessoas, bem como prescreve a obrigatoriedade do ensino de artes na educaçáo básica, representando, assim, um importante caminho para desencadear processos de educação estética. O curso de Pedagogia, portanto, constitui espaço legí- 
timo no que se refere à educaçáo estética do pedagogo. $\mathrm{O}$ trabalho pedagógico desse profissional, configurado na sua dimensão estética, ao gerar processos educativos mais diversificados e envolventes, tende a se tornar mais significativo, particularmente quando se trata de alguma linguagem artística, por exemplo, no âmbito da educação infantil e dos anos iniciais da educação básica. (MORAES, 20I6) ${ }^{7}$

A Pedagogia, concebida como ciência da educação, e o pedagogo, como profissional que pode atuar exercendo diferentes processos educativos (LIBÂNEO, 2002), compreendem um campo de conhecimento teórico-prático representativo de um universo de saberes múltiplos, dentre os quais se destaca o estético. Libâneo (2002, p. 65) reforça que a Pedagogia, ao mobilizar processos educativos, diz respeito a uma "[...] prática cultural, forma de trabalho cultural, que envolve uma prática intencional de produção e internalização de significados." A mesma precisa ter uma intenção humanizadora e crítica, posto que a Pedagogia atua no campo do fenômeno educativo, "[...] como expressão de interesses sociais em conflito na sociedade em que vivemos. É por isso que a pedagogia expressa finalidades sociopolíticas, ou seja, uma direção explícita da ação educativa relacionada com o projeto de gestão social e política da sociedade." (op. cit., p. 66)

Este ensaio destaca a formação inicial do pedagogo por ser a instância que gera condiçóes de desenvolvimento das raízes a partir das quais os hábitos de uma prática reflexiva, crítica e humanizadora irão se consolidar na formação contínua, fundamental ao aperfeiçoamento do pedagogo, particularmente pelas experiências profissionais vivenciadas em plenitude. Os saberes são mutantes e complexos, requerendo atualizaçóes e aprofundamentos constantes, sob pena de esse profissional não desenvolver suas atividades docentes com um nível de qualidade capaz de garantir a efetivação de sua práxis.

À universidade cabe aprofundar o reconhecimento de sua relevância como um polo cultural fundamental para o estudante de Pedagogia em formação inicial, abrangendo açôes no âmbito da extensão, do ensino e da pesquisa. Na pesquisa realizada na referida universidade pública, depoimentos colhidos com diversos estudantes desse curso convergem para essa assertiva. Eles afirmam, por exemplo, que o ingresso na universidade representou um marco em seus processos de formação artístico-cultural, 
tanto no sentido de começar a ter acesso a obras artísticas - peças teatrais, dança, filmes de arte, entre outros - quanto a ter uma formação artística baseada em cursos e oficinas que podem, inclusive, levar à produção de objetos de arte que lhes faculte perceber e desenvolver sua potência criativa:

Acredito que diversos alunos foram descobrir a arte a partir do curso de Pedagogia e acredito que até mesmo vários deles, tem diversos talentos e que ainda não se manifestaram ou até mesmo não deram conta que os possui. Entáo, eu acho que a importância tá nisso. [...] você, a princípio, não percebe essa ação da arte, só percebe quando questionado, quando reflete mesmo sobre essas atividades. (Estudante $03,8^{\circ}$ período, 06/I2)

A formação em Pedagogia, para mim, foi de fundamental importância para esse aguçamento de criatividade. Aqui na Faculdade, nós temos a oportunidade de ampliar nossas ideias; parece que quando chegamos aqui, os professores abrem nossas cabeças. [...] Todos esses profissionais contribuem de maneira essencial para nossa formação, pois ampliaram nossas noções e percepçóes a respeito da arte de modo geral e, mais do que isso, mostraram o quanto a mesma traz "vida" para nosso cotidiano. (Estudante 04, $9^{\circ}$ período, 06/I2)

Esses e tantos outros depoimentos significativos expressam as muitas aprendizagens vivenciadas pelos estudantes, o que demonstra a relevância das iniciativas voltadas à ampliação de um projeto de educação estética no âmbito da formação inicial do pedagogo.

\section{Consideraçóes finais}

A relação entre fome, aprendizagem e afeto articulada por Rubem Alves coaduna-se com a ideia da Pedagogia Antropofágica aqui situada, quando esse autor afirma que "Toda experiência de aprendizagem se inicia com uma experiência afetiva. É a fome que póe em funcionamento o aparelho pensador. Fome é afeto. O pensamento nasce do afeto, nasce da fome." (ALVES, 2002) O ato de comer, a partir de uma necessidade vital 
- a fome -, entendendo-se a fome em sentido amplo, expressa-se como um ato de busca constante, de nutrição não somente fisiológica, mas cultural, espiritual e afetiva.

Ao defendermos uma composição antropofágica do repertório de saberes na formação inicial de estudantes e de professores universitários como um caminho fértil no processo de educação estética, expomos, ao mesmo tempo, uma percepçáo baseada tanto na própria experiência profissional quanto na observação e investigação de percursos formativos de estudantes: quanto mais um sujeito - seja ele estudante ou professor - se manifesta de modo curioso, envolvido, crítico, mais sua desenvoltura e seu repertório cultural e científico vão sendo dinamizados e consolidados, mais se desenvolve o estudioso/pesquisador; quanto mais experiências concretas - de ensino, de pesquisa e de extensão - ele vivencia, mais ele se mostra disposto e aberto ao aprendizado e às intervençôes socioeducativas que lhe surgem.

Em relação ao professor universitário, particularmente, compreendemos que ele precisa exercer essas práticas antropofágicas em sua formação continuada, o que implica estar envolvido em pesquisas e experiências concretas, para atuar como mediador de aprendizagens, sendo que ele mesmo precisa possuir essa perspectiva em si incorporada. Os tem perceber mudanças nos nossos modos de pensar, agir, sentir, pois as experiências concretas tendem a gerar transformaçóes críticas em uma práxis profissional.

Nessa direção, acreditamos ser fundamental, seja para o mediador de aprendizagem seja para o próprio aprendiz, o acesso a saberes práticos e a experiências significativas, guiadas por teorias que as fundamentem.

A perspectiva da antropofagia pode atravessar qualquer campo de saber. Ela compóe uma metáfora importante na criação variada de saberes, que são sempre nutridos por outros, numa 'cadeia alimentar' infinita. A Pedagogia Antropofágica é, pois, essencial ao processo de educação estética de pedagogos, sendo ela uma elaboração permanente, que não pode se dar pontualmente, mas somente no âmbito da formação inicial. Entretanto, o período de formaçáo profissional num curso de graduaçáo/licenciatura de nível superior precisa se tornar algo significativo, uma etapa de estímulos à busca autônoma de saberes por parte desse futuro pedagogo. Nessa di- 
reção, a universidade - e, consequentemente, suas respectivas instâncias financiadoras e gestoras - precisa conjugar esforços na direção da ampliação do corpo de professores e de sua formação, bem como da infraestrutura da instituição, pois são necessárias melhores e maiores possibilidades de criação de açôes pedagógicas que consolidem um projeto de educação estética. Essa atenção à política educacional torna-se um imperativo no atual contexto, se se quer exercer um processo de formaçáo significativa de pedagogos.

A universidade constitui um espaço privilegiado de apreensão e de produçáo de saberes, seja pela via da pesquisa, seja por meio do ensino e da extensão. Essa instituição educativa precisa assumir esse papel de modo mais enérgico, sem negligenciar nenhum dos componentes do tripé universitário que, a nosso ver, são complementares entre si nos processos formativos.

Posto que os saberes docentes são múltiplos (TARDIF, 2007), a formação inicial de pedagogos exige açóes formativas também múltiplas, ações que envolvam aspectos teóricos e práticos, aliadas ainda aos saberes que compóem a trajetória de vida dos estudantes e dos professores, bem como aos saberes presentes no contexto sociohistórico em que se exerce tal formação.

O contexto da formação inicial de pedagogos é, pois, imprescindível para estruturar as raízes de um processo de emancipação estética que a epistemologia da práxis, fundante da formação continuada, irá expandir e consolidar com base numa razão prática, com sólida articulação teórica e em meio a um esforço coletivo para sua efetivaçáo.

\section{Notas}

I O amplo acesso e aprofundamento em relaçấo aos bens e produtos culturais são essenciais a todos os professores de diferentes áreas de conhecimento; entretanto, para efeito de especificação deste estudo, o foco recai sobre a atuação do pedagogo no ensino de artes. Há grande demanda por parte das escolas de educação infantil e das séries iniciais do ensino fundamental em relação ao ensino de arte. E são os pedagogos que atuam nesses níveis de ensino com o citado campo de saber.

2 Para fins de análise e fundamentação deste artigo, tomam-se como referência as políticas educacionais e açôes pedagógicas de uma universidade pública brasileira, sem desprezar experiências vivenciadas em inúmeros contextos universitários.

3 O ato de um humano comer a carne de outro, para saciar a fome ou ainda por questóes psicopatológicas, é mais referenciado atualmente como canibalismo, e não como antropofagia, para diversos autores.

4 Esse questionamento se manifestou nas discussōes em grupo feitas em turmas de um curso de 
Pedagogia durante pesquisa empírica realizada entre 2012 e 2015 .

5 O formato de aula-oficina apreende uma perspectiva que alia, concomitantemente, saberes teóricos e práticos, ou seja, os estudantes são conduzidos, no decorrer de todo o semestre, tanto a desenvolverem estudos teóricos quanto a se envolverem nas discussóes e atividades artísticopedagógicas exercidas em sala de aula, como uma produçáo coletiva, um exercício que envolve música e movimento, a leitura de um texto literário etc., sempre articuladas com os temas pertinentes a cada disciplina.

6 Para uma discussão sobre experiência estética ver: MEIRA, Marly Ribeiro. Filosofia da Criação: reflexões sobre o sentido do sensível. Porto Alegre: Mediaçáo, 2009.

7 Em relatos feitos por estudantes de Pedagogia da referida universidade sob observaçấo há afirmaçôes de que suas diversas práticas pedagógicas, já como professores das escolas locais, se espelharam em práticas artísticas aprendidas na formação inicial.

\section{Referências}

ALVES, Rubem. A arte de produzir fome. São Paulo: Jornal Folha de São Paulo, 29/10/2002.

ANDRADE. Oswald. O Manifesto Poesia Pau-Brasil. São Paulo. In: Jornal Correio da Manhä, março, I924.

. Manifesto Antropófago. In: Revista de Antropofagia. Piratininga, ano I, no I. Maio, 1928.

BARCELOS, Valdo; SILVA, Ivete Souza. Antropofagia cultural brasileira e educação: contribuições ecologistas para uma pedagogia da "devoração". In: Revista Poiesis, n.I, v. I, p. 20-4I, jan./ abr., 2008. DOI: http://dx.doi.org/Io.19I77/prppge.vieI 200820-4I

BONDÍA, Jorge Larrosa. Notas sobre a experiência e o saber de experiência. In: Revista Brasileira de Educação. Jan-Abril, 2002. No I9. DOI: http://dx.doi.org/IO.I590/SI4I324782002000100003.

CANCLINI, Nestor García. Culturas hibridas: estratégias para entrar e sair da modernidade. São Paulo: EDUSP, 2008.

D’AVILA, Cristina. Razão e sensibilidade na docência universitária. In: Revista Em Aberto-INEP, v.29, p.I03-II8, 2016.

. Didática lúdica: saberes pedagógicos e ludicidade no contexto da educação superior. In: Revista Entreidéias: educação, cultura e sociedade. v.3, p. 87-Ioo, 2014.

DUARTE-JUNIOR, João Francisco. A Montanha e o videogame: escritos sobre educação. Campinas-SP: Papirus, 2010.

FRANCO, M. A. Rosário. Pedagogia e prática docente. São Paulo: Cortez, 2012. 
LIBÂNEO, A. Carlos. Ainda as perguntas: O que é Pedagogia, quem é o Pedagogo, o que deve ser o curso de Pedagogia. In: PIMENTA, S. Garrido (org). Pedagogia e pedagogos: caminhos e perspectivas. São Paulo: Cortez, 2002.

MEIRA, Marly Ribeiro. Filosofia da criação: reflexóes sobre o sentido do sensível. Porto Alegre: Mediação, 2009.

MORAES, Ana Cristina. Educação Estética na universidade: antropofagias e repertórios artístico-culturais de estudantes. Curitiba/Fortaleza: CRV/EdUECE, 2016.

PIMENTA, S. Garrido. Formação de professores: saberes da docência e identidade do professor. In: Revista Nuances - vol. III - Setembro. I997. DOI: http://dx.doi. org/IO.I4572/nuances.v3i3.50.

O estágio na formação de professores: Unidade teoria e prática? São Paulo: Cortez, 2006.

RIBEIRO, Darcy. O povo brasileiro: A formação e o sentido do Brasil. São Paulo: Companhia das Letras, I995.

SCHILLER, Friedrich. A Educação estética do homem. São Paulo: Iluminuras, 20 I I.

TARDIF, Maurice. Saberes docentes e formação profissional. 8 ed. Petrópolis: Vozes, 2007.

THERRIEN, Jacques (20I0). Da epistemologia da prática à gestão dos saberes no trabalho docente: Convergências e tensões nas pesquisas. In: DALBEN, A.; DINIZ, J.; SANTOS, L. (Orgs.). Convergências e tensóes no campo da formação e do trabalho docente. XV ENDIPE. Belo Horizonte: Autêntica, 2010, p.307-323.

ZEICHNER, Kenneth. Uma análise crítica sobre a "reflexão" como conceito estruturante na formação docente. In: Revista Educação e Sociedade/CEDES, vol. 29, no I03, p. 535-554, mai/ago, 2008. DOI: http://dx.doi.org/Io.I590/SoIoI73302008000200012 .

Recebido em 24 abr. 2017 / Aprovado em I4 jun. 2018

Para referenciar este texto

MORAES, A. C.; THERRIEN, J. Pedagogia antropofágica no aprofundamento do repertório de saberes culturais de estudantes de pedagogia e seus professores. EccoS - Revista Científica, São Paulo, n. 46, p. 53-69. mai./ago. 2018. Disponível em: <https://doi.org/I0.5585/EccoS.n46.7342>. 
